\title{
Rancang Bangun Kendali Kecepatan Treadmill Menggunakan ECG yang Divisualisasikan Menggunakan Virtual Reality
}

\author{
Kevin Leo Saputra, Tasripan, dan Achmad Arifin \\ Departemen Teknik Elektro, Fakultas Teknologi Elektro, Institut Teknologi Sepuluh Nopember (ITS) \\ e-mail: arifin@bme.its.ac.id
}

\begin{abstract}
Abstrak-Secara umum, subjek yang sedang melakukan latihan kebugaran akan mengalami kejenuhan ketika proses latihan dilakukan terus menerus, hal ini diakibatkan karena kondisi lingkungan yang selalu sama. Pada tugas akhir ini, akan disusun sistem yang dapat mengurangi kejenuhan menggunakan tampilan virtual reality dan mengatur kecepatan treadmill yang bergantung pada nilai heart rate yang dihasilkan oleh ECG dengan Karvonen formula, yang mana digunakan sebagai acuan penentu nilai heart rate dari setiap subjek untuk menentukan nilai minimum dan maksimum heart rate yang mana penggunaannya memerlukan informasi usia dan jenis kelamin. Pengujian ini telah dilakukan pada sembilan subjek yang berusia 22 tahun dan semuanya pria dengan tingkat keberhasilan $\mathbf{7 7 , 7 7 \%}$ terhadap threshold $8.5 \%$ dari puncak sinyal ECG. Perbandingan respon heart rate ketika menggunakan dan tanpa menggunakan virtual reality terhadap setiap orang memiliki respon yang berbeda-beda.
\end{abstract}

Kata Kunci-Virtual Reality, Treadmill, Electrocardiograph.

\section{PENDAHULUAN}

$\mathrm{L}$ ARI merupakan cara yang efisien dan murah untuk mendapatkan kebugaran, dan benefit yang didapatkan melebihi yang diperkirakan. Lari tidak hanya mencegah obesitas, tekanan darah tinggi, penyakit jantung, dan penyakit lain yang berkaitan dengan gaya hidup yang inaktif, selain itu juga menampilkan peningkatan kardiovaskular dan massa tulang, maupun kesehatan mental dan emosi. Studi telah menampilkan, bahkan dengan jumlah lari yang sangat sedikit setiap minggu dapat mengurangi kecenderungan terhadap kegelisahan, tekanan, dan depresi disaat yang bersamaan juga meningkatkan kualitas tidur dan suasana hati secara keseluruhan dan kondisi mental [1].

Kondisi mental seseorang atau biasa disebut dengan "mental state" dapat mempengaruhi bagaimana seseorang berpikir, merasakan sesuatu dan berperilaku dalam kehidupan sehari-hari. Hal tersebut juga mempengaruhi kemampuan anda untuk terlindung dari stress, mengtasi tantang, membangun relasi dan memulihkan kondisi dari halangan hidup. Seseorang akan selalu berusaha mengatasi emosi, atau berusaha berpikir positif. Ketika seseorang mengalami penurunan kondisi mental maka memerlukan motivasi yang dapat berupa zat kimia maupun rangsangan dari luar yang dapat berupa visual. Pada subjek yang melakukan latihan kebugaran cenderung mengalami kejenuhan yang mengakibatkan penurunan motivasi untuk melatih anggota gerak. Menurunnya motivasi ini biasa diakibatkan karena seseorang mengalami kejadian yang berulang-ulang tanpa adanya variasi yang signifikan. Hal ini meningkatkan kondisi depresi seseorang selain karena merasa tidak adanya dorongan dalam mengatasi kondisi saat latihan maupun merasa tidak adanya perkembangan yang terjadi ketika seseorang menjalani proses latihan.

Proses pelatihan ini dapat di atasi dengan mengembangkan teknologi Virtual Reality yang menarik banyak perhatian. Dengan perkembangan virtual reality dapat mengubah kondisi mental seseorang karena mempunyai banyak fitur yang dapat meningkatkan kondisi mental seseorang, selain itu dapat membentuk kondisi lingkungan yang berubah-ubah sesuai dengan kemauan dan pola rehabilitasi yang mau diberikan. Virtual Reality dapat menghemat biaya dan menurunkan kemungkinan terjadinya kecelakaan saat melakukan rehabilitasi ketika subjek melakukan rehabilitasi diluar ruangan. Penggunaan ECG dimanfaatkan untuk memberi umpan balik pada penggunaan treadmill, yang dimanfaatkan sebagai pijakan sehingga dapat menambah sensasi ketika penggunaan alat. ECG digunakan untuk mengatur kecepatan putaran motor secara otomatis sehingga tidak memerlukan kendali secara manual ketika kerja jantung dirasa telah melewati batas kerja maksimum. Dengan adanya fungsi tersebut, maka mekanisme perekaman kondisi jantung dapat dimanfaatkan sebagai data mentah untuk menganalisa perilaku jantung dan mampu memantau kelainan jantung.

\section{DASAR TEORI}

\section{A. Kelistrikan Jantung}

Jantung adalah otot pompa yang memiliki dua fungsi yaitu: (1) mengumpulkan darh dari jaringan-jaringan tubuh dan memompanya ke paru-paru dan (2) mengumpulkan darah dari paru-paru dan memompanya ke seluruh jaringan tubuh. Jantung terletak didalam perlindungan thoraks, posterior dari sternum dan costal dari kartilago, dan sisanya pada permukaan superior dari diafragma. Jantung dapat diasumsikan posisinya miring didalam thoraks dengan dua pertiganya dibagian kiri dari garis tengah [2].

Anatomi internal dari jantung terungkap bahwa jantung memiliki 4 ruang yang terdiri dari otot jantung atau miokardium. Dua ruang bagian atas disebut atrium yang mana sebagai ruang pengumpulan dan dua ruang bagian bawah disebut ventrikel yang mana jauh lebih kuat dan fungsinya untuk memompa darah. Aktivitas jantung dapat diamati dengan 
mengambil informasi berupa sinyal elektrik yang dikeluarkan akibat adanya aktivitas jantung.

\section{B. Segmen Sinyal Jantung}

Siklus kelistrikan jantung mengakibatkan terbentuknya sinyal jantung yang dapat disadap dengan menggunakan elektroda dan digunakan untuk analisa bentuk maupun ritme jantung menggunakan elektrokardiograf. sinyal jantung yang terbentuk memiliki 5 segmen yaitu segment $\mathrm{P}, \mathrm{Q}, \mathrm{R}, \mathrm{S}$ dan T. Segmen sinyal jantung dapat diamati pada Gambar 1. Gelombang sinyal $\mathrm{P}$ kecil diawal, yang mana bersamaan dengan depolarisasi dari atrium. Atrium mulai berkontraksi sekitar 25 milidetik setelah gelombang $\mathrm{P}$ dimulai. QRS complex, yang mana timbul akibat depolarisasi ventrikel. Sinyal elektrik relative kuat, karena otot ventrikel jauh lebih besar dari pada atrium. Ventrikel mulai berkontraksi tidak lama setelah mencapai puncak gelombang $\mathrm{R}$. Gelombang $\mathrm{T}$ yang kecil diakhir, mengindikasi repolarisasi pada ventrikel. Repolarisasi atrium tidak tampak, karena bersamaan saat ventrikel melakukan depolarisasi, dan QRS complex menutupi kejadian elektrik yang lain.

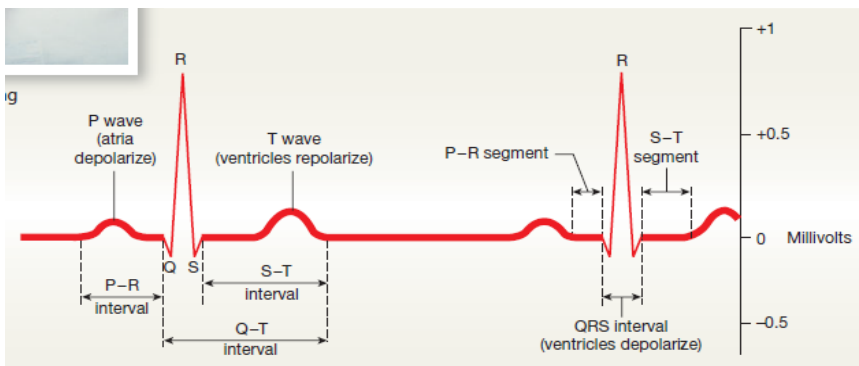

Gambar 1. Segmen sinyal jantung.

Analisa sebuah ECG harus mengukur ukuran dari besar kecilnya perubahan tegangan dan menentukan durasi dan hubungan sementara antara komponen yang bervariasi. Jumlah depolarisasi saat gelombang P dan QRS complex merupakan bagian penting untuk membuat diagnose. Waktu antara setiap gelombang dilaporkan sebagai segmen dan interval. Interval dapat dimanfaatkan untuk melihat gejala aktivitas ruang jantung, seperti interval dari P-R diperpanjang dari awal atrium depolarisasi hingga ke QRS complex (depolarisasi ventrikel) daripada ke bagian $\mathrm{R}$, hal ini disebabkan karena dalam abnormal ECG akan terjadi kesulitan untuk mencari puncak R, dan interval Q-T yang mengindikasi waktu yang dibutuhkan untuk ventrikel melakukan satu siklus depolarisasi dan repolarisasi. Biasanya diukur dari akhir P-R interval daripada bagian bawah gelombang Q [1].

\section{Zona Heart Rate}

Melakukan aktivitas mengarah pada peningkatan metabolism dan permintaan energi dari organisme. Hal ini terlihat pada peningkatan konsumsi oksigen. Mempertimbangkan konsentrasi hemoglobin, jantung merupakan organ yang merespon peningkatan penyediaan oksigen terhadap jaringan aktif. Penggunaan metode heart rate menemukan kadar oksigen tanpa menggunakan Teknik atau instrument yang membatasi latihan. Setiap orang memiliki batas Heart rate yang berbeda tergantung dengan aktivitas, posisi tubuh dan faktor gen. sehingga dengan menggunakan metode pencarian heart rate dapat dibuat batas aman maksimal seseorang melakukan aktivitas. Heart rate rata-rata orang normal saat keadaan istirahat sekitar $70 \mathrm{Bpm}$. Sedangkan untuk atlet biasanya memiliki heart rate sekitar $50 \mathrm{Bpm}$. Hal ini tergantung kondisi kebugaran dan aktivitas yang biasa dilakukan oleh seseorang

\section{Karnoven Fomula}

Karvonen formula merupakan formula matematika yang dapat membantu dalam melakukan Analisa terhadap heart rate yang ditimbulkan oleh aktivitas jantung. Zona latihan berbasis pada tingkat intensitas yang mana merupakan persentase dari perkiraan heart rate maksimum dari setiap individu. Ada enam zona latihan yang berbeda, yang telah disertakan pada Tabel 1. Namun yang pertama kali harus diketahui terlebih dahulu adalah heart rate yang dihasilkan saat berada dalam kondisi beristirahat atau biasa dikenal sebagai resting heart rate (RHR), yang akan digunakan sebagai nilai awal dalam penghitungan Karvonen formula. Sehingga nilai RHR dapat dimanfaatkan untuk mencari batas bawah dan batas atas dari zona latihan dapat dihitung dengan mengikut langkah-langkah sebagai berikut:

1. Menemukan resting heart rate (RHR).

2. Menemukan perkiraan maksimum heart rate (HRmax).

$$
\begin{aligned}
& H R \max (\text { Pria })=220-\text { usia } \\
& H R \max (\text { wanita }=226-\text { usia }
\end{aligned}
$$

3. Menemukan heart rate reserve (HRR).

$$
H R R=H R \max -R H R
$$

4. Menghitung batas bawah dari THR (THRmin). THRmin $=(H R R \times$ LowerIntensity $\%)+R H R$

5. Menghitung batas atas dari THR (THRmax). THRmax $=(H R R \times$ UpperIntensity $\%)+R H R$

Tabel 1. Data Acuan Heart Rate

\begin{tabular}{lr}
\hline \hline Training Zone & Intensity \\
\hline Recovery & $<65 \% \mathrm{HR} \max$ \\
Aerobic & $65 \%-75 \% \mathrm{HR} \max$ \\
Extensive Endurance & $75 \%-80 \% \mathrm{HR} \max$ \\
Intensive Endurance & $80 \%-85 \% \mathrm{HR} \max$ \\
Anaerobic Threshold & $85 \%-90 \% \mathrm{HR} \max$ \\
Maximum Aerobic & $>90 \% \mathrm{HR} \max$ \\
\hline \hline
\end{tabular}

\section{E. Pemrosesan Sinyal Analog}

Aktivitas jantung mengeluarkan sinyal listrik yang dapat dibaca dengan menggunakan elektrokardiografi, yang mana kegunaannya sebagai alat kesehatan yang dapat mendeteksi beda potensial yang terjadi ketika jantung pada segmen-segmen tertentu. Pengambilan sinyal harus menggunakan alat bantu elektroda yang mana ditempelkan pada bagian permukaan kulit untuk menyadap sinyal yang ditimbulkan oleh jantung. Pemasangan elektroda memiliki standar tertentu untuk dapat mengambil sinyal jantung agak lebih efisien dan terhindar dari gangguan atau mungkin interferensi dari sinyal lain seperti otot. Oleh karena itu pemrosesan sinyal analog ECG membutuhkan beberapa tahap karena sinyal jantung yang timbul hanya memiliki nilai beda potensial yang kecil dan mudah untuk terganggu oleh gangguan dari faktor lainnya. Prinsip kerja ECG tampak pada Gambar 2, yang mana menjelaskan serangkaian tahap untuk melakukan pemrosesan sinyal untuk melakukan pengukuran beda potensial yang ditimbulkan oleh aktivitas 
jantung. Sinyal tersebut dilewatkan kedalam penguat instrumentasi, lalu perlu dilakukan filterisasi untuk mengeliminasi sinyal yang tidak diinginkan dan menghilangkan gangguan yang diakibatkan oleh faktor lainnya, dan dikonversi kedalam bentuk sinyal digital yang dapat diproses lebih lanjut di permrosesan digital.

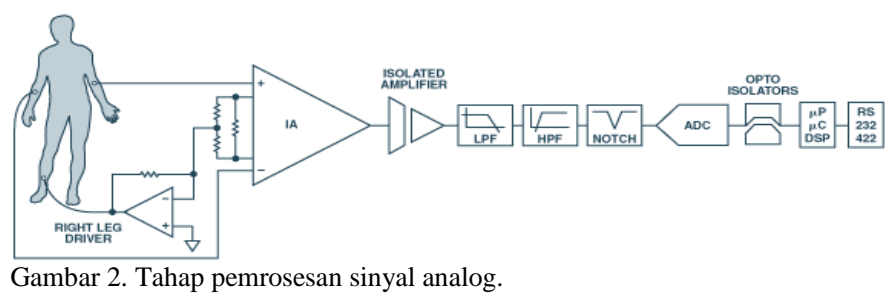

\section{F. Pemrosesan SInyal Digital}

Setelah sinyal analog telah dapat dihasilkan, sinyal tersebut baru akan dimasukkan ke dalam mikrokontroler melalui ADC (Analog to Digital Converter) untuk diubah menjadi nilai digital agar dapat dikomputasi. Pemrosesan sinyal digital terdiri dari pemrosesan sinyal analog ke digital, filter digital, dan komunikasi serial melalui kabel. Pemrosesan sinyal digital diperlukan agar sinyal dapat dianalisa lebih baik, sehingga keluaran yang diinginkan sesuai dengan yang diperlukan.

\section{G. Virtual Reality}

Virtual Reality (VR) pertama kali digunakan pada abad 1980an. Oxford English Dictionary (OED) menunjukkan penggunaan virtual reality lebih awal, dimana virtual reality bukanlah computer. Namun merupakan teknologi yang menggunakan komputerisasi untuk mensintensis realitas bersama. Sistem VR sederhana termasuk dalam video game rumah yang menghasilkan tampilan grafis tiga dimensi (3D) dan suara stereo dan dikendalikan oleh operator menggunakan joystick atau keyboard computer. Sistem lebih lanut - seperti untuk pelatihan pilot dan pengalaman hiburan imersif - dapat termasuk head-mounted display atau layer proyeksi berukuran besar untuk menampilkan gambar, suara 3D, dan treadmill yang mana mengizinkan operator untuk berjalan melalui lingkungan virtual [3].

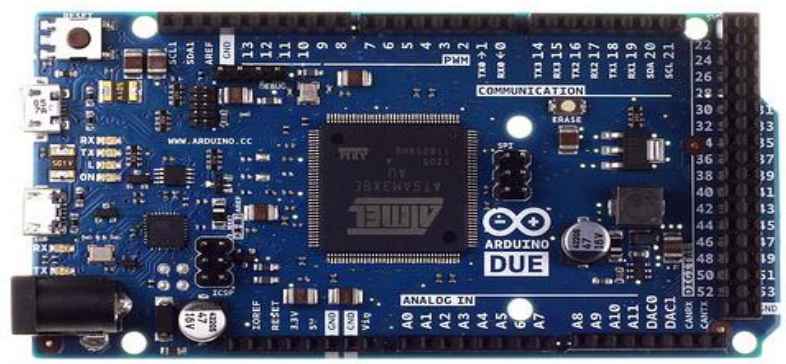

Gambar 3. Arduino due.

\section{H. Ardunino Due}

Pada pemrosesan sinyal digital digunakan mikrokontroler Arduino Due yang berbasis ARM yang dapat dilihat pada Gambar 3. Mikrokontroler ini merupakan produk dari Arduino yang menggunakan prosesor ATSAM3X8E AU yang memiliki performa 32bit. Mikrokontroller ini dipilih karena banyak fitur yang telah diberikan dan memiliki DMA, ADC, Timer, pin digital maupun PWM yang cukup banyak, dan dapat beroperasi maksimal pada kecepatan $84 \mathrm{MHz}$ yang mana sangat dibutuhkan ketika melakukan pemrosesan sinyal digital secara real-time.

\section{PERANCANGAN SISTEM}

Bab perancangan sistem ini menjelaskan sistem secara keseluruhan mulai dari pengolahan sinyal melalui perangkat keras ECG hingga perangkat lunak. Perangkat keras yang digunakan antara lain, instrumentasi ECG, Arduino Due, kontroler motor treadmill, dan HMD Proview ${ }^{\text {TM}}$. Sedangkan, perangkat lunak teridiri dari sofware Arduino (IDE) untuk pembuatan kode program dan Unity Engine yang digunakan sebagai software pengembangan visual yang dapat ditampilkan pada layar HMD.

Perancangan perangkat keras meliputi perancangan instrumentasi ECG yang digunakan untuk mengolah sinyal murni dari aktivitas jantung dimana instrument ini terdiri dari 5 tahap, dapat dilihat pada gambar dan kontroler motor treadmill yang digunakan untuk mengontrol kecepatan motor treadmill sesuai dengan perubahan aktivitas jantung yang diambil data hasil pengolahan digital.

Sedangkan, perancangan perangkat lunak meliputi proses akuisi data, filter digital, teorema pantomkins yang digunakan untuk melakukan segmentasi pada pengolahan sinyal yang telah melewati filter digital dimana dapat dilihat pada gambar dan penggunaan Karvonen formula untuk menentukan batas heart rate,

\section{A. Diagram Blok Sistem}

Seperti dijelaskan sebelumnya, bahwa alat ini membutuhkan 3 perangkat utama, yaitu instrumentasi ECG yang berguna sebagai pengolah sinyal murni, Arduino Due sebagai pengolah sinyal digital dengan berbasis ARM, dan Head-Mounted Display yang digunakan untuk tampilan visual berupa dunia virtual, sehingga dapat memberikan pengalaman yang lebih Instrumentasi ECG menggunakan dua baterai 9V sebagai sumber, karena membutuhkan tegangan referensi $+5 \mathrm{~V}$ dan $-5 \mathrm{~V}$ untuk memberi suplai daya pada rangkaian tersebut. Alas an penggunaan baterai 9V karena pada instrumentasi ECG tidak membutuhkan arus yang besar untuk suplai seluruh komponen, dan juga ketika menggunakan baterai $9 \mathrm{~V}$ hanya tidak akan terlalu membebani regulator yang menstabilkan dan menurunkan tegangan dari $9 \mathrm{~V}$ menjadi $5 \mathrm{~V}$.

Arduino Due merupakan mikrokontroler yang mana masukkannya diambil dari instrumentasi ECG yang akan diubah dari data analog menjadi data digital terlebih dahulu menggunakan Analog-to-Digital Converter. Setelah menjadi data digital, maka sinyal akan dilewatkan pada digital filter yang mana gunanya untuk membatasi frekuensi bandwidth yang ingin disegmentasi. Hasil digital filter akan dimasukkan pada teorema Pantompkins yang digunakan untuk menganalisa segmen QRS complex hingga menjadi sinyal keluaran berupa nilai heart-rate yang real-time. Setelah itu dimasukkan pada metode Karvonen yang mana akan digunakan untuk menentukkan penggolongan beban dari kerja jantung yang mana akan dikirimkan datanya sebagai masukkan dari treadmill dan software Unity. 
Head-Mounted Display Proview ${ }^{\mathrm{TM}}$ merupakan media untuk menampilkan gambar grafis dari PC yang mana berperan disini sebagai layar kedua dan memiliki tampilan seperti layar lebar yang memiliki sudut pandangan yang cukup lebar. Gambar grafis disini merupakan gambar keluaran dari software Unity yang digunakan untuk mengembangkan grafis dan membuat rute perjalanan.

Keseluruhan blok diagram ditunjukkan oleh Gambar 4. dibawah ini. Bagian-bagian pada blok diagram diatas terdiri dari:

1. Instrumentasi ECG

Instrumen ini berperan sebagai pengolahan sinyal analog dari pergerakan aktivitas jantung dengan menggunakan tiga elektroda.

2. Mikrokontroler

Data dari instrumentasi ECG diolah menggunakan mikrokontroler Arduino Due.

3. Unity

Data keluaran dari Arduino Due digunakan sebagai masukkan kedalam software Unity yang mana akan ditampilkan melalui HMD.

4. VR

Tampilan yang menggunakan fitur HMD dengan menampilkan secara stereoskopis sehingga menambah pengalaman pemakai.

5. Treadmill

Bagian dari keseluruhan kerja yang dikontrol menggunakan keluaran mikrokontroler dan dimanfaatkan sebagai media untuk menambah pengalaman pemakai.

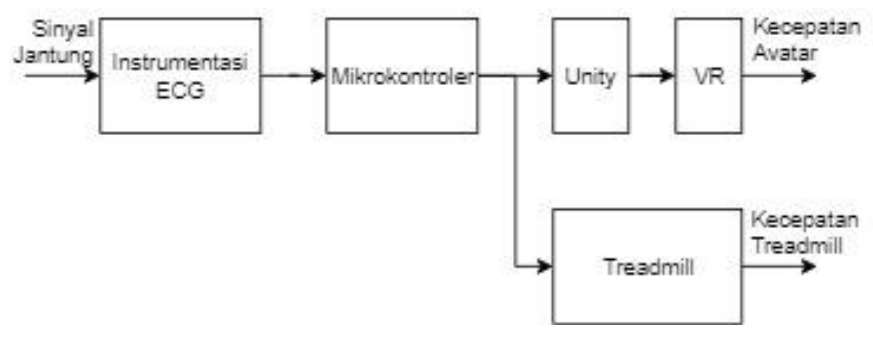

Gambar 4. Diagram blok sistem.

\section{PENGUJIAN DAN PEMBAHASAN}

Pengujian-pengujian yang dilakukan meliputi pengujian Instrumentasi ECG, pengujian teorema Pantompkins, pengujian heart-rate secara real-time, pengujian komunikasi treadmill dan pengujian Visualisasi. Pengujian alat ini secara real dilakukan di laboratorium AJ-203 dan B-205 Institut Teknologi Sepuluh Nopember (ITS), Surabaya, Jawa Timur 60111.

\section{A. Pengujian ECG}

Sebelum sinyal ECG dari elektroda diproses maka sinyal tersebut perlu dikuatkan terlebih dahulu, karena sinyal yang didapatkan dari elektroda terlalu kecil. Setelah melalui penguatan, maka sinyal analog akan perlu di filter dengan menggunakan filter analog untuk dapat menjadi masukkan pada mikrokontroler berikut merupakan data hasil dari pengolahan sinyal analog dari instrumentasi ECG.
Pengujian low pass filter telah disertakan pada Tabel 2. Dimana didapatkan error sebesar $18 \mathrm{~Hz}$ dari target frekuensi cut-off $100 \mathrm{~Hz}$, namun kesalahan ini masih dapat ditoleransi karena frekuensi dari segmen QRS berada pada frekuensi 6-15 $\mathrm{Hz}$ dan frekuensi bandwidth standar $0.05 \mathrm{~Hz}$ hingga $100 \mathrm{~Hz}$.

Tabel 2.

Hasil Pengujian LPF

\begin{tabular}{cccc}
\hline \hline Frekuensi & Tegangan Output & Tegangan Input & Gain \\
\hline 10 & 20.8 & 20.8 & 1 \\
20 & 19.8 & 20.8 & 0.95192 \\
30 & 19 & 20.8 & 0.91346 \\
40 & 18.2 & 20.8 & 0.875 \\
50 & 17.6 & 20.8 & 0.84615 \\
60 & 16.4 & 20.8 & 0.78846 \\
70 & 15.2 & 20.8 & 0.73077 \\
80 & 14.4 & 20.8 & 0.69231 \\
90 & 13.2 & 20.8 & 0.63462 \\
100 & 12.2 & 20.8 & 0.58654 \\
200 & 6 & 20.8 & 0.28846 \\
\hline \hline
\end{tabular}

Dilanjutkan dengan high pass filter yang telah disertakan pada Tabel 3. Dimana terdapat error sebesar $0.08 \mathrm{~Hz}$ dari target frekuensi cut-off $0.05 \mathrm{~Hz}$. Namun kesalah ini masih dapat ditoleransi karena frekuensi segmen QRS tidak terpotong oleh error pada high pass filter.

Tabel 3.

Hasil Pengujian HPF

\begin{tabular}{cccc}
\hline \hline Frekuensi & Tegangan Output & Tegangan Input & Gain \\
\hline 0.25 & 4 & 7.2 & 0.55556 \\
0.5 & 11.2 & 15.2 & 0.73684 \\
0.75 & 14.4 & 16.8 & 0.85714 \\
1 & 19 & 20.8 & 0.91346 \\
5 & 19 & 20.8 & 0.91346 \\
10 & 19 & 20.8 & 0.91346 \\
\hline \hline
\end{tabular}

Setelah melalui pemrosesan filter maka sinyal akan melewati penguatan kembali, lalu akan dilewatkan pada rangkaian penjumlah sehingga nilai dari amplitudo berada minimum $0 \mathrm{~V}$ dan bernilai positif dan terakhir akan dilewatkan pada rangkaian proteksi yang mana gunanya untuk membatasi tegangan yang masuk ke mikrokontroler. Hasil keluaran terlihat pada Gambar 5.

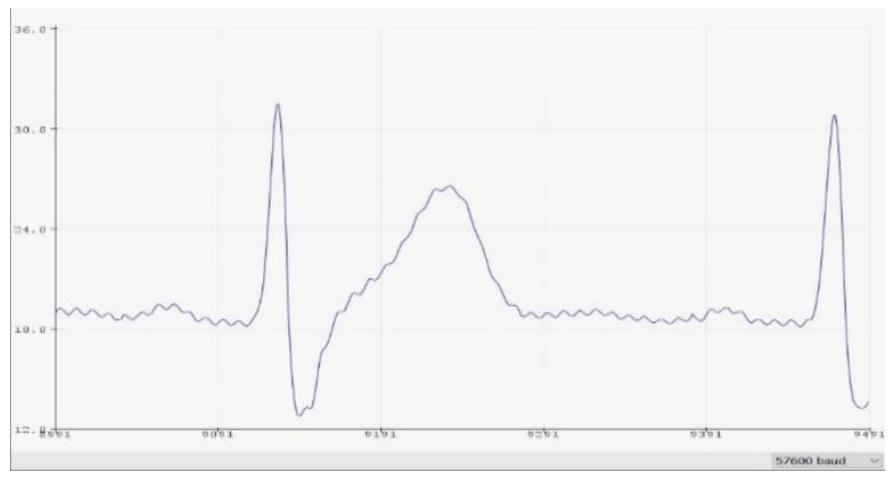

Gambar 5. Sinyal ECG murni.

Sinyal yang didapatkan mendapatkan noise pada frekuensi tertentu yang mana disebabkan karena adanya kesalahan dari kabel yang menghubungkan ke alat selanjutnya. Gangguan juga dapat disebabkan oleh kesalahan posisi pemasangan elektroda, maupun kualitas dari elektroda 


\section{B. Pengujian Perangkat Lunak}

Terdapat tiga tahap, yakni filter digital, teorema Pantompkins, dan pemrosesan heart-rate secara real-time. Pengambilan sinyal dapat dipengaruhi oleh peletakkan elektroda, yang mana dapat meningkatkan kemungkinan adanya noise. Oleh karena itu diperlukan beberapa filter dalam pemrosesannya.

1. Pengujian Digital Filter

Hasil keluaran dari analog terdapat noise yang signifikan, oleh karena itu dibutuhkan filter digital. Hasil keluaran dari filter digital, telah membentuk keluaran yang memuaskan seperti sinyal jantung sebagaimana mestinya. Pengujian ini dilakukan di laboratorium AJ-203. Hasil dari digital filter dapat dilihat pada Gambar 6.

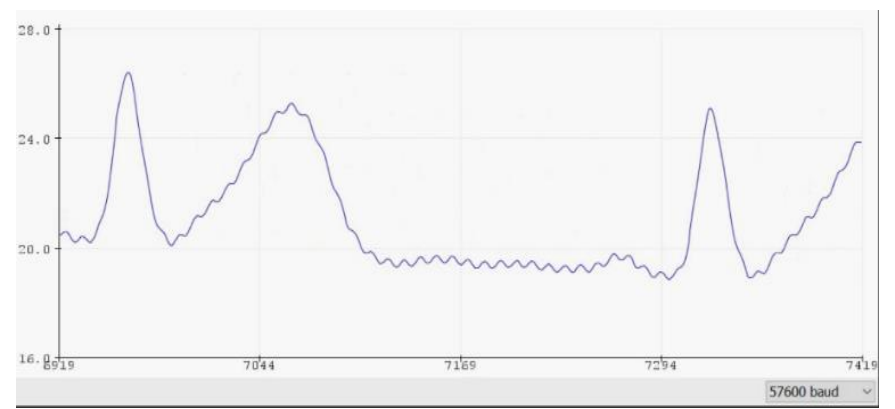

Gambar 6. Hasil filter.

\section{Pengujian Teorema Pantompkins}

Pengujian teorema Pantompkins, merupakan pengujian untuk melakukan proses segmentasi sinyal yang bertujuan untuk menampilkan secara jelas segmen QRS hingga yang mana bertujuan untuk mencari segmen $R$ yang sangat terlihat paling besar ketika dibandingkan dengan segmen lainnya. Setelah segmen R didapatkan, maka akan melaui thresholding diubah menjadi bentuk sinyal digital yang hanya berisi nilai 1 dan 0 , yang mana 1 berarti ketika didapati segmen $\mathrm{R}$ pada sinyal, sedangkan selain segmen $\mathrm{R}$ sinyal akan diberi nilai 0 . Hasil dari proses ini dapat dilihat pada Gambar 7.

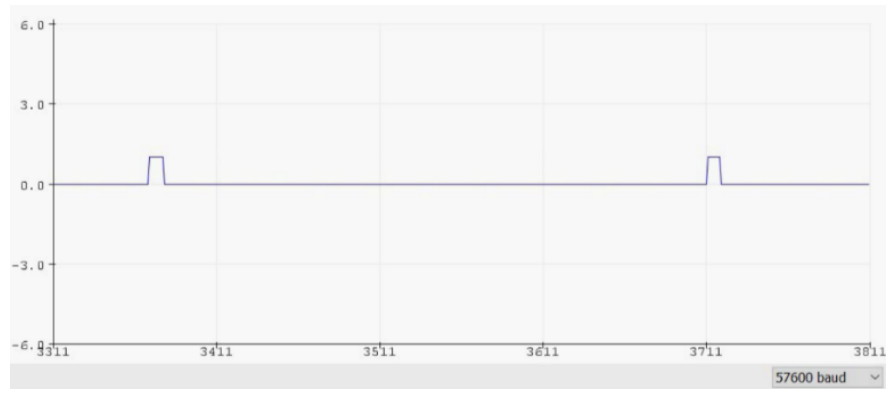

Gambar 7. Hasil thresholding.

\section{Pengujian Heart-rate secara Real-time}

Pengujian heart-rate secara real-time dilakukan setelah melakukan proses teorema pantompkins. Dimana menghitung interval waktu antara segmen R ke R selanjutnya. Namun ketika menghitung secara real-time maka interval tersebut perlu dicari rata-ratanya terlebih dahulu sehingga bisa didapatkan nilai ratarata interval. Ketika telah didapatkan nilai rata-rata interval, maka dapat langsung dihitung nilai heart rate per menit (BPM). Hasil pengukuran dapat dilihat pada Gambar 8.

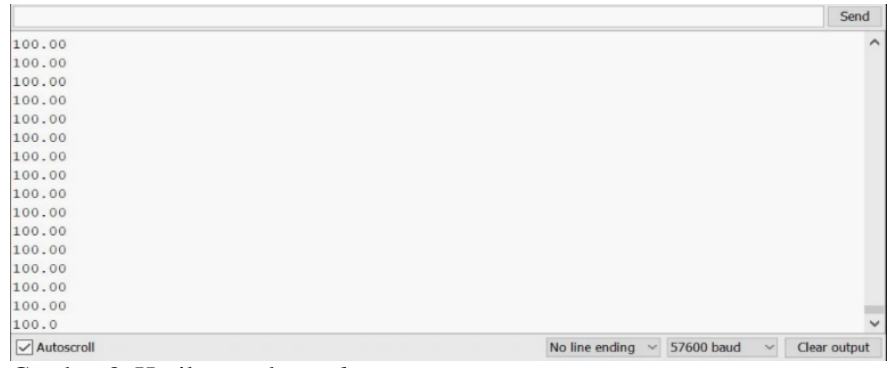

Gambar 8. Hasil pengukuran heart rate.

\section{Pengujian Visual}

Pada tahap pengujian rancangan visual dilakukan dengan menguji jalannya tampilan pada layar dunia virtual. Tampilan menggunakan head-mounted display proview ${ }^{\mathrm{TM}}$ sebagai pengolah citra. Secara keseluruhan bidang yang telah didesain beserta dengan lingkungan yang seperti air, pohon dan langit dari tampak atas dapat dilihat pada Gambar 9. Penentuan rute ditandai pada titik merah. Penggunaan rute dibuat dengan target perpindahan dari satu tempat ke tempat selanjutnya agar tidak terlalu jauh, karena hal ini bisa mengakibatkan bertabrakan antara avatar didunia virtual dengan objek-objek yang ada dilingkungan.

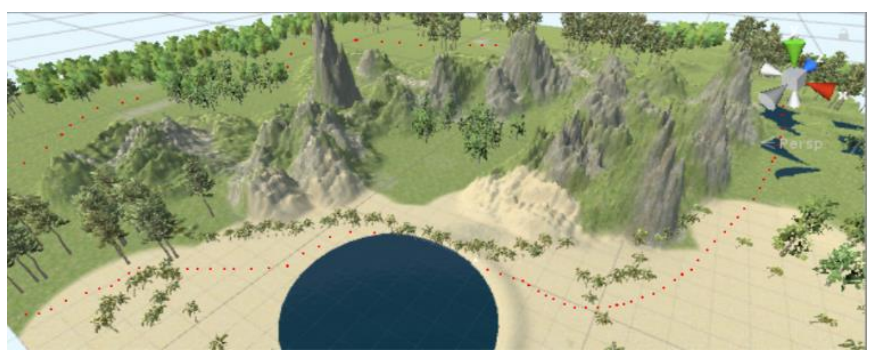

Gambar 9. Tampilan rute berwarna merah.

\section{Pengujian Keseluruhan Sistem}

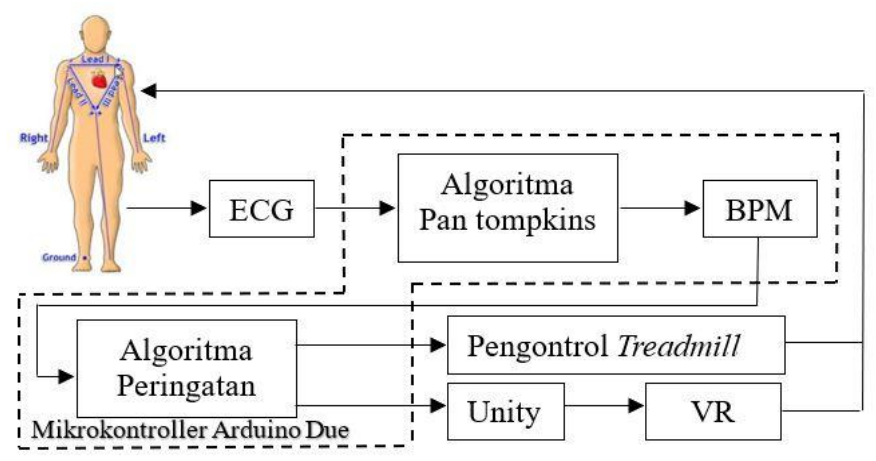

Gambar 10. Diagram keseluruhan system.

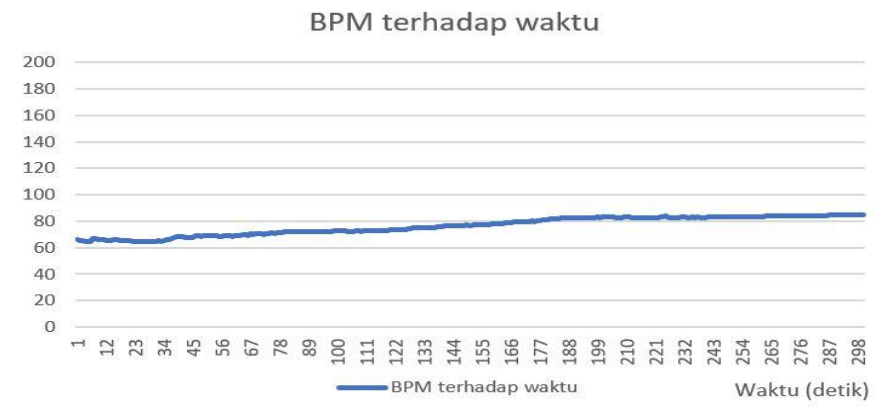

Gambar 11. Respon BPM dengan VR. 


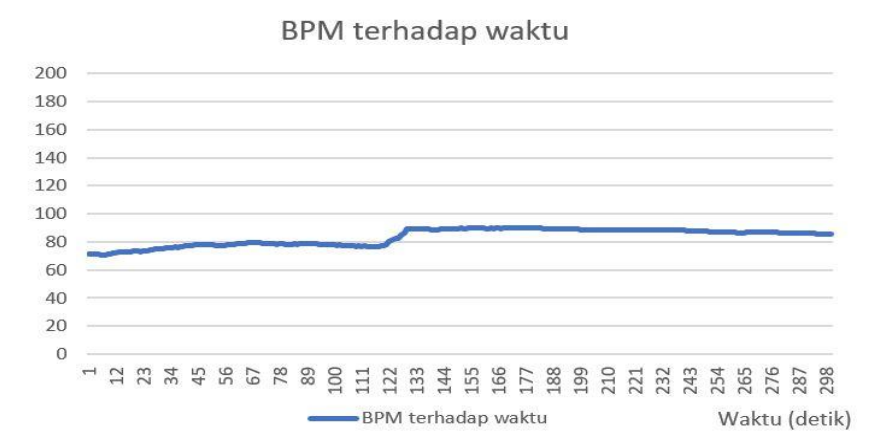

Gambar 12. Respon BPM tanpa VR.

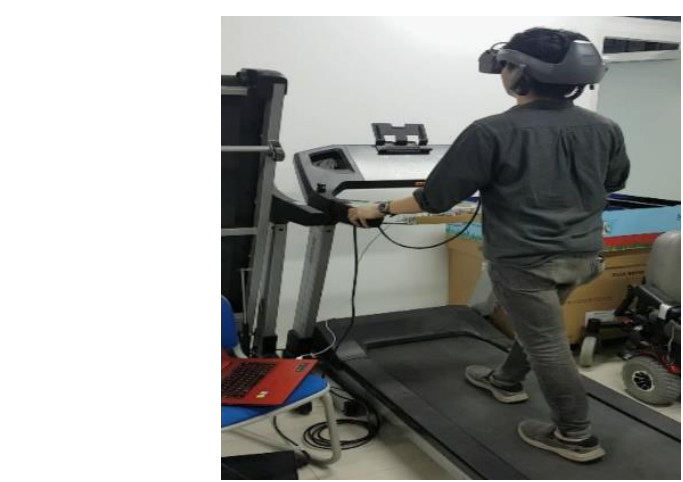

Gambar 13. Subyek.

Pada tahap pengujian keseluruhan sistem dilakukan seperti pada Gambar 10. Dimana peran ECG langsung berguna sebagai pengatur kecepatan dari treadmill dan bersamaan kecepatan gerak dari avatar pada VR. Respon BPM ketika menggunakan VR dapat dilihat pada Gambar 11, sedangkan respon BPM tanpa VR dapat dilihat pada Gambar 12.

Alat ini telah diuji pada 9 subjek dengan tingkat keberhasilan $77,77 \%$. Contoh salah satu subyek dapat dilihat pada Gambar 13.

\section{KESIMPULAN}

Berdasarkan perancangan, pengujian, dan analisa sistem yang telah dilakukan dapat ditarik beberapa kesimpulan dari tugas akhir ini sebagai berikut:

a. Berdasarkan pengamatan, pemasangan alat memberikan sedikit ketidaknyamanan karena memiliki penempatan kabel untuk virtual reality dan ECG.

b. Respon penggunaan virtual reality terhadap BPM memiliki dampak yang berbeda-beda.

c. Hasil pengambilan data memiliki tingkat keberhasilan $77,77 \%$ terhadap batas threshold $8,5 \%$ dari puncak sinyal.

d. Pengukuran BPM dapat terganggu oleh lingkungan sekitar terutama lokasi subyek berdiri.

\section{DAFTAR PUSTAKA}

[1] Paul A. Iaizzo, Handbook of Cardiac Anatomy, Physiology, and Devices. University of Minesota, 1984.

[2] F. H. Martini, J. L. Nath, and F. Edwin, Anatomy \& Physiology. Pearson, 2012.

[3] J. Glover, Unity for Human Beings. Zenva: Zenva, 2016. 